\title{
AS MODULAÇÕES DO DIREITO CONTEMPORÂNEO EM UM BREVE EXERCÍCIO DE FILOSOFIA DO DIREITO
}

\author{
VARICTIONS OF CONTEMPORARY LAW IN A BRIEF \\ EXERCISE OF PHILOSOPHY OF LAW
}

\begin{abstract}
Jeanine Nicolazzi Philippi*
RESUMO: Pretendemos neste trabalho analisar as modulações do direito contemporâneo em um tempo regido, cada vez mais, em sua dinâmica decisória, por processos de negociação, no qual a redistribuição das formas de participação na composição das regras do jogo e os instrumentos atuais de gestão colocam em marcha uma nova engrenagem jurídica que deixa de operar como um sistema de normas a priori - ou seja, uma função terceira -, para converter-se em rede de regras flexíveis, adaptáveis às injunções de um mundo que opera sob o imperativo de que tudo é possível. A compreensão dessas transformações implica - em um primeiro plano - uma breve incursão na história recente do pensamento jurídico no qual podemos distinguir dois tipos de Estados aos quais associamos dois modelos de direito: o liberal e o social. Em um segundo momento, o texto procura esclarecer como as bases da construção jurídica dos Estados nacionais não suportaram os impactos decorrentes da redefinição das fronteiras políticas em um mundo economicamente globalizado onde o monopólio estatal da legislação está sendo progressivamente suplantado pela capacidade normativa de inúmeras organizações multilaterais, grupos econômicos nacionais, instituições financeiras internacionais e corporações empresariais multinacionais com poder decisório, que condicionam a direção dos negócios públicos e a produção do direito estatal.
\end{abstract}

PALAVRAS-CHAVE: Direito contemporâneo. Processo de negociação. Rede de regras flexíveis.

ABSTRACT: Our intention in this work is to analyze the variations in contemporary law at a time increasingly governed by the dynamics of decision-making power through negotiation procedures in which the redistribution of the forms of participation in the composition of the rules at stake and the current means of administration set in motion a new judicial organization. This organization ceases to operate as a system of a priori norms - thus, a third function - to be converted into a network of flexible rules, adaptable to the dictates of a world that operates under the imperative that anything is possible. The understanding of these transformations requires, at first, a brief foray into the recent history of judicial thinking where we can distinguish two types of states associated with two legal models, the liberal and the social. Secondly, the text seeks to clarify how the bases of judicial construction of nation states do not tolerate impacts resulting from redefining political frontiers in a globalized world economy where the legislative state monopoly is being progressively supplanted by the normative ability of innumerable multilateral organizations, national economic groups, international financial institutions and multinational business corporations with decision-making power, stipulating the direction of public business and state law making.

KEYWORDS: Contemporary law. Negotiation procedure. Flexible rules network.

* Doutora em Direito, Professora dos Cursos de Graduação e Pós-Graduação em Direito - na área de Teoria e Filosofia do Direito - da Universidade Federal de Santa Catarina, Tutora do PET/Direito da UFSC 
Toda disciplina apresenta um limite epistemológico inevitável. Marcados por essa contingência, nos resignamos, com frequência na academia, à exploração das fronteiras conhecidas de um campo específico do saber, certos de que, com método, chegaremos à verdade final.

Empenhados na preservação das certezas da representação, negamos - com horror - os encontros faltosos que nos apresentam o real - o (i)mundo do qual emergimos, queiramos ou não, como resposta. Sob a proteção dos enunciados anônimos que nos preservam da dura tarefa de uma enunciação eticamente comprometida, perpetuamos o trabalho de degradação da palavra e de aniquilamento do seu portador. Essa impostura leva o pensamento à imobilidade e nos convoca como protagonistas de um jogo de máscaras que oculta uma repetição básica: a resistência em questionar a mestria fundante dos ídolos da tribo e em referenciar uma certa invenção. Assim, é sempre oportuno distinguir outro horizonte de reflexão onde, além da certeza, a pergunta insiste lembrando ao sujeito que ele pode constituir um ponto de partida onde se deixa sempre a desejar... (SILVA, p. 4)

Essa abertura nos restitui o sentido de um questionamento propriamente filosófico, ou seja, o valor da indagação que, paradoxalmente, busca e rompe a estabilidade do saber. Por isso, é lícito dizer que o ser daquele que questiona é desejo que perdura a despeito da ausência do objeto. (JURANVILLE, 1987, p. 16) Pontuando a dimensão dessa errância, Platão já dizia no Banquete: Eros é fundamentalmente uma falta... Nenhum dos deuses poderia filosofar, pois a filosofia já é seu apanágio. $O$ mesmo se pode dizer dos ignorantes, nenhum dos quais deseja a filosofia, porque o mal da ignorância é tornar contentes consigo mesmos os que, não sendo bons nem sábios, cuidam que o são... Ninguém deseja senão o de que se julga privado. (PLATÃO, 1961, p. 57-63)

Quando a falta é a referência, as indagações filosóficas roubam a cena das ordens unívocas, imprimindo um movimento crítico ao pensamento que permite expor distintas fronteiras de enunciação, nas quais a segurança monótona das reproduções da verdade cede espaço às tensões de uma reflexão desestabilizadora articulada à ética singular do bem-dizer que evoca a responsabilidade do sujeito em relação àquilo que ele enuncia, como também a sua implicação nos enunciados que acolhe como se fossem seus.

A possibilidade dessa resposta inspirou, neste trabalho, a análise das modulações do direito em um tempo regido, cada vez mais, em sua dinâmica decisória, por processos de negociação, em que a redistribuição das formas de participação na composição das regras do jogo e os instrumentos atuais de gestão colocam em marcha uma nova engrenagem jurídica que deixa de operar como um sistema de normas a priori - ou seja, uma função terceira -, para converter-se em uma rede de regras flexíveis, adaptáveis às injunções de um mundo que opera sob o imperativo de que tudo é possível...

A compreensão dessas transformações implica - em primeiro plano - uma breve incursão na nossa história recente do pensamento jurídico em que podemos distinguir dois tipos de estado aos quais associamos dois modelos de direito: o liberal e o social. No quadro 
do liberalismo político, compreendíamos a ordem jurídica como conjunto de regras gerais, abstratas e previsíveis destinadas à proteção dos direitos individuais, da propriedade e dos contratos. (ROTH, In: FARIA, 1996) Nesse contexto, estudar direito seria, então, aprender uma técnica capaz de controlar a sociedade por meio de instrumentos normativos formais convertidos em medidas universais de comportamento - sem vinculação com conteúdos materiais -, organizados a partir de um sistema hierarquizado que subordina as normas inferiores às superiores em um movimento linear de fundamentação ou validade. A essa compreensão dos ordenamentos jurídicos agregávamos, também, a funcionalidade dos princípios que estabeleciam a livre circulação de pessoas, idéias e bens contra a interferência ou arbítrio do estado.

Essa aposta na capacidade autorreguladora da sociedade começou, no entanto, a mostrar seus limites já no final do século XIX. Em um tempo no qual a ideia da luta pela vida contribuiu para o sucesso de uma teoria que conseguiu tornar aceitável - como explicação válida para o progresso humano - uma seleção fundada na conquista do espaço pelo animal -, o laissez-faire dos devoradores mais fortes (LACAN, 1998, p. 123) levou ao reconhecimento da necessidade de uma regulamentação positiva que tornasse controlável os riscos de explosão de litígios e anomia da sociedade.

Assim, a ordem jurídica converte-se - especialmente a partir da Segunda Guerra Mundial - em um instrumento estratégico para viabilizar a realização política de objetivos e valores indispensáveis à manutenção de uma certa legitimidade do Estado. Acompanhando essas mudanças o direito social foi pensado não apenas para definir as regras do jogo, mas, sobretudo, para modificar os resultados desse jogo, alterando, implicitamente, as suas regras. Por essa razão, ele transforma, também, o horizonte do Judiciário, convocando-o a operar a partir de estratégias hermenêuticas que permitem ajustar o discurso do intérprete à necessidade de respostas aos problemas ligados à redistribuição dos recursos comuns e à desigualdade social. (FARIA, 1999, p. 276)

Essas regras de julgamento que facultam a adaptação argumentativa das normas à realidade promovem, sem dúvida, um novo tipo de racionalidade para o direito, mas, ao mesmo tempo, conservam a forma jurídica herdada da tradição liberal, uma vez que continuam a ser dadas no âmbito de uma unidade lógico-formal - sem lacunas ou antinomias - com base na qual é sempre possível deduzir decisões sobre o que é de direito. (p. 44/45)

As bases dessa construção jurídica dos estados nacionais não suportaram, contudo, os impactos decorrentes da redefinição das fronteiras políticas em um mundo economicamente globalizado. Nele, o monopólio estatal da legislação - que permitiu a concepção do sistema jurídico como um complexo unitário e hierarquizado de normas está sendo progressivamente suplantado pela capacidade normativa de inúmeras organizações multilaterais, grupos econômicos nacionais, instituições financeiras 
internacionais e corporações empresariais multinacionais com poder decisório, que condicionam a direção dos negócios públicos e a produção do direito estatal. (p. 14/15)

Em termos de técnica jurídica a consequência mais expressiva dessa transformação é a flexibilização da ordem jurídica dos estados que, segundo os teóricos do direito reflexivo, abre espaço para a produção de um tipo inédito de regras sociais ajustadas aos interesses dos indivíduos implicados nas diversas prescrições normativas. Para os entusiastas da soft law, o caráter democrático dessas deliberações é garantido por uma racionalidade procedimental que orienta a formulação das decisões negociadas e pela capacidade de discussão razoável dos sujeitos que atuam nos diversos foros de negociações. (p. 23/24)

Como podemos observar, o direito reflexivo possui pontos comuns com o modelo do direito social. Eles partilham um modo muito próximo de encarar o direito como um ensaio ou uma experiência de constituição de novas práticas normativas e de distintas estruturas de poder. Não devemos, portanto, tomá-los como paradigmas colidentes no âmbito do pensamento jurídico (p. 277), mas, tampouco, podemos confundi-los. Como vimos acima, o direito social é um instrumento estratégico de resposta aos problemas de redistribuição de recursos e poderes no âmbito dos estados nacionais.

$O$ direito reflexivo, em contrapartida, surge em um processo de desterritorialização da política - marca indelével da escalada da globalização econômica - que tem como um dos seus corolários, a organização de um sistema de governos privados, no qual os indivíduos - convocados a negociar o texto das regulações sociais - se encontram cada vez mais impotentes para concretizar acordos que dizem respeito as suas necessidades fundamentais. Nesse território despojado de espaço público, o direito refletivo representa o resultado das negociações normativas - ou seja, dos ajustes de detalhes - que não podem ultrapassar o quadro geral da regulação - fixado pelas instâncias decisórias do mercado - apresentado como realidade insuperável. (ROTH, In: FARIA, 1996, p. 26)

Essa técnica jurídica vital para a eficácia do quadro de (des)regulação social requerido pelo movimento da economia globalizada implica, também, uma alteração da discricionariedade das esferas de ação do Judiciário. (FARIA, In: FARIA, 1999, p. 131) Nesse novo contexto, as regras de julgamento que permitiam - no quadro do direito social - o ajuste argumentativo das normas para uma solução adequada dos problemas da sociedade, cedem espaço a um trabalho interpretativo contínuo que reconstrói - por meio das decisões - o texto normativo social.

Para que tenham a sua eficácia garantida, as negociações das regras que implementam as diretrizes fixadas pelas instâncias decisórias do mercado exigem que o estado dote sua ordem jurídica de plasticidade aumentando as possibilidades de escolha, decisão e controle oferecidas à magistratura. Hoje, é recorrente na teoria do direito a distinção do conteúdo normativo - o início da significação jurídica - da norma propriamente dita - a decisão na qual o aplicador do direito procede à valoração dos dados objetivos e subjetivos presentes nos casos levados à apreciação do Judiciário, submetendo, assim, o texto normativo à sua própria avaliação. 
A composição desse direito flexível - no qual o intérprete torna-se coparticipante do processo de criação de normas jurídicas -, como podemos perceber, é vital para o curso tranquilo da globalização econômica, na medida em que os veredictos judiciais como os ditames do mercado - são imunes às pressões políticas e sociais, o que facilita, de forma significativa, os ajustes de detalhes necessários à implementação incondicional do modelo de redenção capitalista.

Assim, na contraface das justificativas de adequação da ordem jurídica ao desenvolvimento das sociedades contemporâneas, a diferença de escala entre o conteúdo normativo e a decisão nos leva a compreender - com Agamben - a configuração de um espaço jurídico vazio próprio ao estado de exceção. (AGAMBEN, 1999, p. 79) A marca desse campo onde o mínimo de vigência formal coincide com o máximo de aplicação real (p. 58), vemos impressa em julgados dos nossos Tribunais superiores como, por exemplo, o voto-vista do Ministro Eros Roberto Grau no Agravo regimental n. ${ }^{\circ} 3034-2$ de 21/09/2006 em que, entendendo ser o caso em análise, uma exceção, argumenta: como observa Karl Schimitt, as normas só valem para as situações normais. A normalidade da situação que pressupõem é um elemento básico do seu "valer". A propósito, Maurice Hauriou menciona: “... é muito justa sta idéia que as normas são feitas apenas para um certo estado normal da sociedade, e que, se este estado normal é modificado, é natural que as leis e suas garantias sejam suspensas."... "As leis são muito bonitas, mas é preciso ter tempo de fazê-las, e trata-se de não estar morto antes que elas não sejam feitas."

Continuando o raciocínio o ministro Eros Grau acrescenta: o estado de exceção é uma zona de indiferença entre o caos e o estado da normalidade, uma zona de indiferença capturada pela norma. De sorte que não é a exceção que se subtrai à norma, mas ela que, suspendendo-se, dá lugar à exceção... apenas desse modo ela se constitui como regra, mantendo-se em relação com a exceção. A esta Corte, sempre que necessário, incumbe decidir regulando também essas situações de exceção. Ao fazê-lo, não se afasta do ordenamento, eis que aplica a norma à exceção desaplicando-a, isto é, retirando-a da exceção. Ao final do voto, afirma, ainda, que: não estamos aqui para prestar contas a Montesquieu ou Kelsen, porém para vivificarmos o ordenamento, todo ele... Não somos meros leitores dos seus textos - para o que bastaria a alfabetização - mas magistrados que produzem normas, tecendo e recompondo o próprio ordenamento.

Nesse voto, o Ministro Eros Grau cita a obra de Agamben Homo sacer - o poder soberano e a vida nua. As páginas do texto ao qual faz referência pertencem ao capítulo intitulado $O$ paradoxo da soberania no qual Agamben escreve: o paradoxo da soberania se enuncia da seguinte forma: "o soberano está, ao mesmo tempo, dentro e fora do ordenamento jurídico"... A especificação "ao mesmo tempo" não é trivial: o soberano tendo o poder legal de suspender a validade da lei, coloca-se legalmente fora da lei. Isto significa que o paradoxo pode ser formulado também deste modo: "a lei está fora dela mesma", ou então: "eu soberano, que estou fora da lei, declaro que não há um fora da 
lei."... É este o sentido último do paradoxo formulado por Schimitt, quando escreve que a decisão soberana "demonstra não ter necessidade do direito para criar o direito." (AGAMBEN, 2002, p. 24-26)

O estado de exceção - como estrutura fundamental da política - emerge em nosso tempo sempre ao primeiro plano e tende, por fim, a tornar-se regra. (p. 27) Nesse espectro, vemos o campo - a matriz política do domínio totalitário - se definir como o paradigma do mundo em que vivemos, onde, segundo Hannah Arendt, tudo é possível... (AGAMBEN, 2002, p. 43-44; 2004, p. 131) Hoje, adverte Agamben, o retorno desse estado de exceção efetivo ao estado de direito não é possível, pois o que está em questão agora são os próprios conceitos de estado e de direito. (AGAMBEN, 2004, p. 131)

\section{REFERÊNCIAS}

AGAMBEN, Giorgio. Estado de exceção. São Paulo: Boitempo, 2004

AGAMBEN, Giorgio. Homo sacer - o poder soberano e a vida nua. Belo Horizonte: Editora UFMG, 2002 , p. $24 / 26$

ARENDT, Hannah. As origens do totalitarismo. São Paulo: Companhia das Letras, 1989, p. $477 / 478$

FARIA, José Eduardo. Democracia e governabilidade - os direitos humanos à luz da globalização econômica. In: FARIA, Direito e globalização econômica, op. cit., p.131

FARIA, José Eduardo. O direito na economia globalizada. São Paulo: Malheiros, 1999, p. 276

JURANVILLE, Alain. Lacan e a filosofia. Rio de Janeiro: Jorge Zahar, 1987, p. 16

LACAN, Jacques. Escritos. Rio de Janeiro: Jorge Zahar, 1998. p. 123

PLATÃO. O Banquete. São Paulo: Editora Atena, 1961. p. 57/63.

ROTH, André-Noël. O direito em crise: fim do Estado moderno. In: FARIA, José Eduardo (Org.). Direito e globalização econômica - implicações e perspectivas. São Paulo: Malheiros, 1996

SILVA, Cyro Marcos. Vinte anos depois de quê? Juiz de Fora: inédito, p. 4 